Journal for

ImmunoTherapy of Cancer

\section{Bivalent therapeutic vaccine against HPV16/18 genotypes consisting of a fusion protein between the extra domain A from human fibronectin and HPV16/18 E7 viral antigens}

To cite: Arribillaga L,

Echeverria I, Belsue V, et al. Bivalent therapeutic vaccine against HPV16/18 genotypes consisting of a fusion protein between the extra domain $\mathrm{A}$ from human fibronectin and HPV16/18 E7 viral antigens. Journal for ImmunoTherapy of Cancer 2020;8:e000704. doi:10.1136/jitc-2020-000704

- Additional material is published online only. To view, please visit the journal online (http://dx.doi.org/10.1136/jitc2020-000704).

Accepted 10 May 2020

Check for updates

(c) Author(s) (or their employer(s)) 2020. Re-use permitted under CC BY-NC. No commercial re-use. See rights and permissions. Published by BMJ.

For numbered affiliations see end of article.

Correspondence to Dr Juan José Lasarte; jjlasarte@unav.es

\section{ABSTRACT}

Background In vivo targeting of human papillomavirus (HPV) derived antigens to dendritic cells might constitute an efficient immunotherapeutic strategy against cervical cancer. In previous works, we have shown that the extra domain A from murine fibronectin (mEDA) can be used to target antigens to toll-like receptor 4 (TLR4) expressing dendritic cells and induce strong antigen-specific immune responses. In the present study, we have produced a bivalent therapeutic vaccine candidate consisting of the human EDA (hEDA) fused to E7 proteins from HPV16 and HPV18 (hEDA-HPVE7-16/18) and evaluate its potential as a therapeutic vaccine against cervical cancer.

Materials and methods Recombinant fusion proteins containing HPV E7 proteins from HPV16 and HPV18 virus subtypes fused to hEDA were produced and tested in vitro on their capacity to bind TLR4 and induce the production of tumor necrosis factor- $\alpha$ or interleukin (IL)-12 by human monocytes and dendritic cells. The immunogenicity and potential therapeutic activity of the vaccine in combination with cisplatin or with the TLR3 agonist molecules polyinosinic-polycytidylic acid (Poly IC) or Poly ICLC was evaluated in mice bearing subcutaneous or genital orthotopic HPV16 TC-1 tumors.

Results hEDA-HPVE7-16/18 prototype vaccine binds human TLR4 and stimulate TLR4-dependent signaling pathways and IL-12 production by human monocytederived dendritic cell. Vaccination with hEDA-HPVE7-16/18 induced strong HPVE7-specific Cytotoxic T lymphocyte (CTL) responses and eliminated established tumors in the TC-1-based tumor model. The antitumor efficacy was significantly improved by combining the fusion protein with cisplatin or with the TLR-3 ligand Poly IC and especially with the stabilized analog Poly ICLC. Moreover, hEDAHPVE7-16/18+Poly ICLC induced full tumor regression in $100 \%$ of mice bearing orthotopic genital HPV tumors. Conclusion Our results suggest that this therapeutic vaccine formulation may be an effective treatment for cervical tumors that do not respond to current therapies.

\section{INTRODUCTION}

Human papillomavirus (HPV) infection is the main cause of cervical cancer. ${ }^{1}$ Among the $>150 \mathrm{HPV}$ types identified, 12-14 HPV types have been categorized as high-risk HPV because of their oncogenic activity in cervical cancer, ${ }^{2}$ HPV16 and HPV18 being responsible for $>70 \%$ of all cervical cancer cases. ${ }^{3}$ Prophylactic HPV vaccines are exhibiting great promise in reducing the burden of this disease. ${ }^{4}$ However, there is limited progress toward the development of immune therapeutic strategies for those women already infected with HPV who do not benefit from the current prophylactic vaccines. It is believed that T-cell immune responses, in particular against E7 protein, may play an important role in resolution of HPV-induced lesions. ${ }^{5}$ Thus, a vaccination strategy able to activate strong E7-specific T-cell immune responses might be contemplated as therapeutic alternative for cervical carcinoma.

The unique capacity of dendritic cells (DC) to take up antigens, generate major histocompatibility complex (MHC)-peptide complexes and elicit immune responses has prompted many laboratories to use DC in clinical trials. However, ex vivo manipulation of DC for the production of DC-based vaccines is expensive, time consuming and difficult to standardize. ${ }^{6}$ Therefore, a procedure to target DC with antigens in vivo would greatly facilitate vaccination protocols. $^{7-12}$ Since maturation of DCs is an essential step to trigger adaptive immune responses, ${ }^{13}$ in previous works we chose a toll-like receptor 4 (TLR4) protein agonist (the extra domain 
A from fibronectin (EDA) ) to simultaneously target the antigen to DCs and induce their maturation. Vaccination with fusion proteins containing murine EDA (mEDA) and a cognate antigen induce strong antigen-specific T-cell responses with antiviral, antibacterial or antitumor potential. ${ }^{14-17}$ We found that the fusion protein mEDAHPVE7-16 containing the EDA from murine fibronectin targets HPV E7 protein (from HPV16 genotype) to DCs and induce strong antitumor $\mathrm{CD}^{+}$T-cell responses. ${ }^{15}$ In the present study, we have conducted the preclinical development for a fusion protein EDA-HPVE7 in order to move this vaccine candidate to clinical trials in patients. We aim to select a candidate vaccine incorporating the human version of EDA (hEDA) fused to E7 proteins from HPV16 and HPV18 (hEDA-HPVE7-16/18). We have compared various candidates on their relative abilities to bind TLR4, stimulate TLR4-dependent signaling pathways, induce HPVE7-specific CTL responses and eliminate established tumors in various TC-1-based models. Combination of vaccines and chemotherapy or immunological adjuvants such as the TLR3 agonist Poly IC and its stabilized analog Poly ICLC was also evaluated. The often poor correlation observed between efficacy in the widely used subcutaneous TC-1 tumor model and clinical trials against HPV-related malignancies prompted us to evaluate the therapeutic efficacy of our vaccine in a more realistic and predictive in vivo model for HPV-associated genital cancer based on orthotopic implantation of tumor cells. ${ }^{18}$ We found that hEDA-HPVE7-16/18 in combination with Poly ICLC adjuvant induced E7-specific CD8 ${ }^{+}$ T-cell effector responses and achieved a complete therapeutic response in this tumor model.

\section{MATERIALS AND METHODS Cell lines and mice}

TC-1 cells expressing the oncogenes HaRas, HPV16-E6 and HPV16-E $7^{19}$ were obtained from the American Type Culture Collection (LGC Promochem, Molsheim, France). Its variant TC-1 P3 (A15) cell line with downregulated MHC class I expression ${ }^{20}$ was kindly provided by Dr TC Wu (MD, USA). TC-1 cells expressing luciferase (LC-1 Luc) were then generated by lentiviral infection. ${ }^{18}$ THP-1 human monocyte-derived cells were obtained from The American Type Culture Collection, Manassas, Virginia, USA). Cells were grown in complete medium (CM) consisting of RPMI-1640 supplemented with $10 \%$ fetal calf serum, $100 \mathrm{U} / \mathrm{mL}$ penicillin, $100 \mu \mathrm{g} / \mathrm{mL}$ streptomycin, $2 \mathrm{mM} \mathrm{L}$-glutamine and $50 \mu \mathrm{M}$ 2-mercaptoethanol.

Specific pathogen-free, female C57BL/ 6 wild-type mice aged 7-10 weeks (Charles River) were used in compliance with the ethical directives of the Swiss and Spanish veterinary authorities. They were housed in appropriated animal care facilities during the experimental period and handled following the international guidelines required for experimentation with animals.

\section{Peptides and reagents}

Synthetic peptides were purchased from Genecust (Dudelange, Luxembourg) and dissolved in 10\% dimethyl sulfoxide in phosphate-buffered saline (PBS). The purity of the peptides was $>80 \%$. Montanide was provided by SEPPIC and Berna-Biotech (Bern). Polyinosinic-polycytidylic acid (Poly IC) was purchased from InvivoGen (San Diego, California, USA) and was diluted in PBS before injection. Poly-ICLC (Hiltonol, a synthetic poly-IC, stabilized with polylysine and carboxymethylcellulose) was kindly provided by Dr Andrés Salazar (Oncovir, NW Washington, District of Columbia, USA). Lipopolysaccharide (LPS) from Escherichia coli 055:B5 was purchased from Sigma (Madrid, Spain).

The hEDA-HPVE7-16 and hEDA-HPVE7-16/18 were produced in E. coli BL21 using a T7 expression vector and purified from inclusion bodies by size exclusion chromatography (Biotecnol, Oeiras, Portugal). The mEDAHPVE7-16 protein was produced at CIMA as previously described. ${ }^{15}$ The levels of endotoxin were below 0.1 $\mathrm{EU} / \mu \mathrm{g}$ protein as tested by Quantitative Chromogenic Limulus Amebocyte Lysate assay (Cambrex, Walkersville, Maryland, USA).

\section{Sample processing for transmission electron microscopy}

For ultrastructural studies by transmission electron microscopy, cells from each treatment were adhered to poly-L-lysine-coated coverslips and processed as previously described with minor modifications. ${ }^{21}$ Ultrathin, 70 $\mathrm{nm}$ thick sections of epoxy resin 812 embedded samples were obtained with an Ultracut UCT ultramicrotome (Leica Microsystems), transferred to 200 mesh Nickel EM grids (Gilder, Lincolnshire, UK) and stained with $3 \%$ aqueous uranyl acetate $(10 \mathrm{~min})$ and lead citrate $(2 \mathrm{~min})$ (Electron Microscopy Science). Sections were visualized on a JEOL JEM 1200 EXII electron microscope operating at $100 \mathrm{kV}$ (JEOL, Tokyo, Japan). DC and T cells can be distinguished by transmission electron microscopy, due to the distinctive features of both cellular types..$^{22} \mathrm{DC}$ are larger than T cells, with a less electron-dense nucleus and an abundant cytoplasm in which large amount of organelles, specially mitochondria, endoplasmic reticulum, endosomes and lysosomes, are distributed throughout the cell volume. T cells are smaller and more spherical, with a reduced cytoplasm and a highly electron-dense nucleus occupying the majority of the cell volume, with the organelles accumulated in one area of the cytoplasm.

\section{In vitro analysis of $\mathrm{DC}$ activation}

Human DCs were generated from monocytes obtained from $80 \mathrm{~mL}$ of blood. Briefly, peripheral blood mononuclear cells (PBMCs) were separated using a Ficoll gradient, and $\mathrm{CD} 14^{+}$cells were enriched using CD14 microbeads (Miltenyi Biotec, Bergisch Gladbach, Germany). These cells were plated in 96-well plates at $10^{6} \mathrm{cells} / \mathrm{mL}$ in culture medium supplemented with GM-CSF (Peprotech, London, UK; $1000 \mathrm{U} / \mathrm{mL}$ ), and interleukin (IL)-4 (Peprotech; $1000 \mathrm{U} / \mathrm{mL}$ ). They were subsequently cultured for 5 
days $\left(37^{\circ} \mathrm{C}, 5 \% \mathrm{CO}_{2}\right)$, with fresh medium containing cytokines added on day 4 .

At day 5 , cells were cultured in the presence of various concentrations of EDA proteins $(2,1,0.1$ and $0.01 \mu \mathrm{M})$, $0.1 \mu \mathrm{g} / \mathrm{mL}$ LPS or culture medium. After 48 hours, supernatants were harvested and IL-12 (p70) was measured by ELISA according to the manufacturer's instructions (BD-Pharmingen, San Jose, California, USA).

\section{In vitro analysis of monocyte/macrophage activation}

THP-1 cells were plated at $0.2 \times 10^{6}$ cells/well in 96-well plates using $\mathrm{CM}$ and then cultured with different concentrations of the EDA proteins, $0.1 \mu \mathrm{g} / \mathrm{mL}$ of LPS, or left untreated for 15 hours. TNF- $\alpha$ release was then quantified in the culture medium using a commercial ELISA assay (BD-Pharmingen) according to manufacturer's instructions.

\section{Binding assays to TLR4 expressing cells}

To test whether the recombinant proteins were able to bind to TLR4 expressing cells, we used HEK293 expressing human TLR4-MD2-CD14 (HEK TLR4; Invivogen) or LacZ (HEK LacZ; InvivoGen) as a negative control. Cells were pulsed with $0.5 \mu \mathrm{M}$ of the Alexa Fluor 488-labeled proteins (Alexa Fluor 488 Microscale Protein Labeling Kit; Invitrogen, Paisley, Scotland) for 1 hour at $4^{\circ} \mathrm{C}$, washed with PBS and analyzed by flow cytometry.

\section{Immunization experiments and measurement of immune responses}

For interferon (IFN)- $\gamma$ ELISPOT assays, mice were immunized as described in the 'Results' section. When indicated, mice received two immunizations at days 1 and 8 . In some experiments, vaccination with the recombinant proteins was combined with intraperitoneal administration of cisplatin at days 5 and 8 ( $5 \mathrm{mg} / \mathrm{kg}$ body weight). PBMCs were prepared from tail-blood and purified on lympholyte M (Cedarlane CL 5035) gradients. Tissues (spleen and cervix-vagina (CV)) were harvested after sacrifice and single-cell suspensions were obtained as previously described. ${ }^{23} 24$

IFN- $\gamma$ ELISPOT assays were performed as previously described $^{23}$ using Multiscreen-HA 96-well plates (MAHA S4510, Millipore; Darmstadt, Germany), antiIFN- $\gamma$ monoclonal antibody (R4-6A2, Becton Dickinson Pharmingen; Allschwil, Switzerland), biotinylated antiIFN- $\gamma$ monoclonal antibody (XMG1.2, Becton Dickinson Pharmingen) and streptavidin-AP (Roche). One or four hundred thousand cells/well were incubated in duplicate with $1 \mu \mathrm{g} / \mathrm{mL}$ of $\mathrm{H}-2 \mathrm{Db}$ restricted $\mathrm{E} 7_{49-57}$ peptide or medium alone (control wells). For CV cells, $3 \times 10^{4}$ bone marrow-derived dendritic cells/well were used as antigenpresenting cells and incubated for 1 hour with $\mathrm{E} 7_{49-57}$ peptide or medium alone, prior to addition of $1 \times 10^{5} \mathrm{CV}$ cells. Following 16-24hours, E7-specific responses were defined as the number of IFN- $\gamma$ spots $/ 10^{5}$ cells in the E7-stimulated wells minus the number of IFN- $\gamma$ spots $/ 10^{5}$ cells in the control wells $(<3$ spots/well).
Tetramer and T-cell labeling was performed as previously described, ${ }^{25}$ using phycoerythrin (PE)-conjugated $\mathrm{E} 7_{49-57}$ and $\mathrm{L}_{165-173}$ (as a control), H-2Db-restricted tetramers (TetE7 and TetL1, respectively; TCMetrix; Epalinges, Switzerland) and allophycocyanine (APC)-labeled CD $8 \alpha$ (clone 53-6.7). The proportion of $\mathrm{TetE}^{+} \mathrm{CD}^{+} \mathrm{T}$ cells among total cells was calculated after subtraction of the background, which was measured using control TetL1 $(<20$ events/CV). Cell acquisition and analysis were performed using a Gallios Flow Cytometer (Beckman Coulter) and FlowJo Software (Tree Star).

\section{Tumor treatment}

\section{TC-1-based subcutaneous tumor models}

TC-1, TC-1 Luc or TC-1 P3 (A15) cells $\left(1 \times 10^{5}, 3 \times 10^{5}\right.$ or $1 \times 10^{5}$ cells/mouse, respectively) were injected into the shaved back (left side) of C57BL/6 mice in $200 \mu \mathrm{L}$ of PBS. At days 7 (when the tumors reached $5 \mathrm{~mm}$ in diameter) and 14, the mice were treated subcutaneously in the back (right side) with the indicated immunogens and/ or adjuvants in the same mixture. In addition, as a positive control of tumor growth, mice were challenged with tumor cells and later treated with PBS only. Tumor size (presented as the average of two perpendicular diameters $(\mathrm{mm}))$ was measured at regular intervals. Mice were sacrificed when the mean tumor diameter was $>18 \mathrm{~mm}$.

\section{Orthotopic tumor model}

To induce genital tumors, anesthetized diestrus synchronized mice pretreated with $4 \%$ nonoxynol-9 (N9, Igepal; Sigma) were challenged intravaginally with 12,50020,000 TC-1-luc cells at day $1{ }^{18}$ Genital tumor growth was monitored by bioluminescence using a Xenogen imaging system (Xenogen/Caliper Life Science, kindly provided by CIF, UNIL, Lausanne) as previously described. ${ }^{18}$ Vaccination was initiated 8 days after genital tumor implantation.

\section{Statistical analyses}

Immune responses were analyzed using non-parametric and unpaired $\mathrm{T}$ tests. $\mathrm{P}$ values $<0.05$ were considered to be statistically significant. Kaplan-Meier plots were used to assess survival, and differences were analyzed using the log-rank test (GraphPad Prism; GraphPad Software, California, USA).

\section{RESULTS}

\section{Linkage to EDA improves T-DC synapse dimensions}

Fusion of an antigen to mEDA favors antigen uptake by TLR4 expressing DC and improves its presentation to antigen-specific T cells. ${ }^{14}$ To get further insight on this improvement of antigen presentation, we studied the synaptic structure with a better spatial resolution by examining T-DC synapses by electron microscopy. Thus, DCs were incubated with equimolar amounts of SIINFEKL peptide, ovalbumin (OVA) or the fusion proteins EDASIINFEKL and EDA-OVA. As a negative control, DCs were 
A
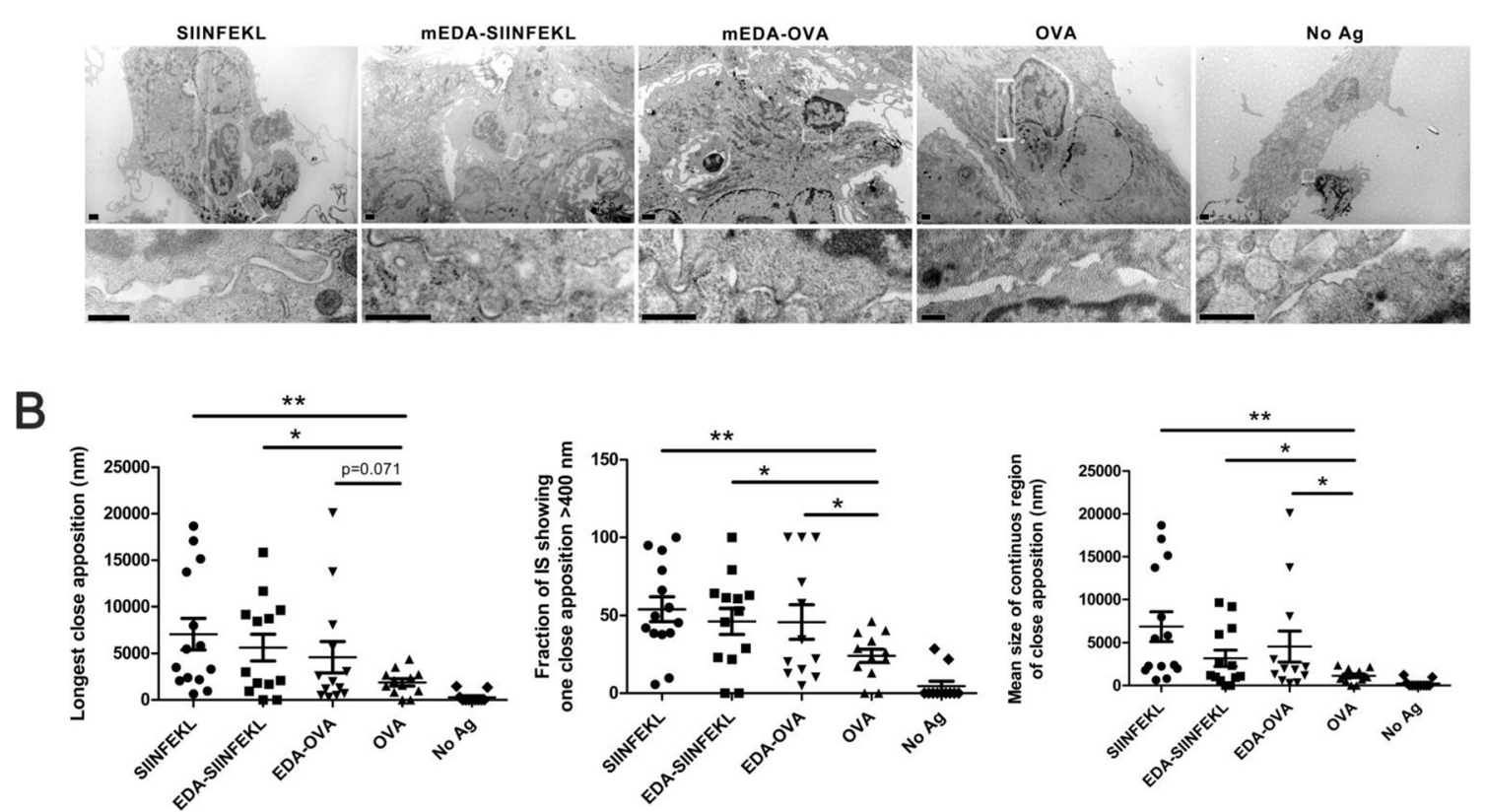

Figure 1 Linkage of ovalbumin (OVA) antigens to extra domain $A(E D A)$ improves immunological synapse. Dendritic cell (DC) incubated with equimolar amounts of SIINFEKL, EDA-SIINFEKL, EDA-OVA, OVA or left untreated, were co-cultured with purified CD $8^{+} \mathrm{T}$ cell from OT-I mice. Then cells were fixed, resin embedded and thin sectioned to be visualized by electron microscopy. (A) Representative micrographs from each group (upper row) and details of contacting areas or synapses (lower row). Magnification bars in upper row correspond to $0.5 \mu \mathrm{m}$, and in lower row correspond to $200 \mathrm{~nm}$. (B) Analyzes of longest close apposition $(\mathrm{nm})$, the fraction of the synapses showing one close apposition $>400 \mathrm{~nm}$ and the mean size of continuous region of close apposition corresponding to 10-12 conjugates/group, measured in electron micrographs from thin sections of cells. Results are representative of two independent experiments. ${ }^{*} \mathrm{P}<0.05,{ }^{* *} \mathrm{p}<0.01$.

maintained with culture medium alone. After an overnight incubation, $\mathrm{CD} 8^{+} \mathrm{T}$ cells from OT-1 transgenic mice were added to the DC cultures and incubated for $30 \mathrm{~min}$, fixed and analyzed by electron microscopy as described in 'Materials and methods' section. In figure 1A, representative micrographs from each group (upper row) and details of contacting areas or synapses (lower row) are included. It was found that length of close appositions, the fraction of the immunological synapse (IS) or the size of the IS regions of close apposition were significantly increased when DC were pre-incubated with the antigen. SIINFEKL peptide, which does not require antigen internalization or intracellular processing, induced close apposition between T cells and DC. On the other hand, OVA protein, which requires antigen processing, was significantly less efficient in the promotion of close appositions. However, both EDA-SIINFEKL and EDAOVA, significantly improved DC-T-cell interactions indicating that antigen presentation to OT- T cells was clearly favored (figure 1B). This enhancement in DC-T-cell close appositions correlates with an improvement in T-cell activation (T-cell proliferation and IFN- $\gamma$ production) reported in previous works ${ }^{14-16}$ and indicates that EDA fusion to antigen proteins induces DC activation and favors antigen presentation to $\mathrm{T}$ cells.

\section{Therapeutic efficacy of mEDA-HPVE7-16 alone in TC-1 tumor models}

Immunization of mice with mEDA-HPVE7-16 fusion protein induced antitumor $\mathrm{CD} 8^{+} \mathrm{T}$-cell responses and protected mice from tumor challenge with TC-1 cells. ${ }^{15}$ In line with these previous results, we found that intratumor administration of five doses of mEDA-HPVE7-16 fusion protein ( $3 \mathrm{nmol}$ at days 3, 4, 5, 6 and 7 after tumor challenge) induced tumor rejection in $50 \%$ of animals. The antitumor efficacy was higher when mice were challenged with TC-1 cells expressing the reporter gene luciferase (TC-1 Luc), despite the animals received three times more tumor cells $\left(3 \times 10^{5}\right.$ cells per mice), suggesting that these cells are more immunogenic because the ectopic expression of the reporter gene. However, the antitumor efficacy was reduced importantly in mice challenged with TC-1 P3 (A15) with downregulated MHC class I expression, a common feature associated with most HPVassociated cervical cancers. ${ }^{20}$ Indeed, therapeutic efficacy was reduced from $50 \%$ for TC-1 or $77 \%$ for TC-1 Luc to $25 \%$ for TC-1 P3 (A15) (figure 2).

\section{Therapeutic efficacy of mEDA-HPVE7-16 in combination with Poly IC adjuvant}

Once observed that the antitumor effect of the mEDAHPVE7-16 vaccine alone was limited in the tumor model with low MHC expression, we evaluated the beneficial 

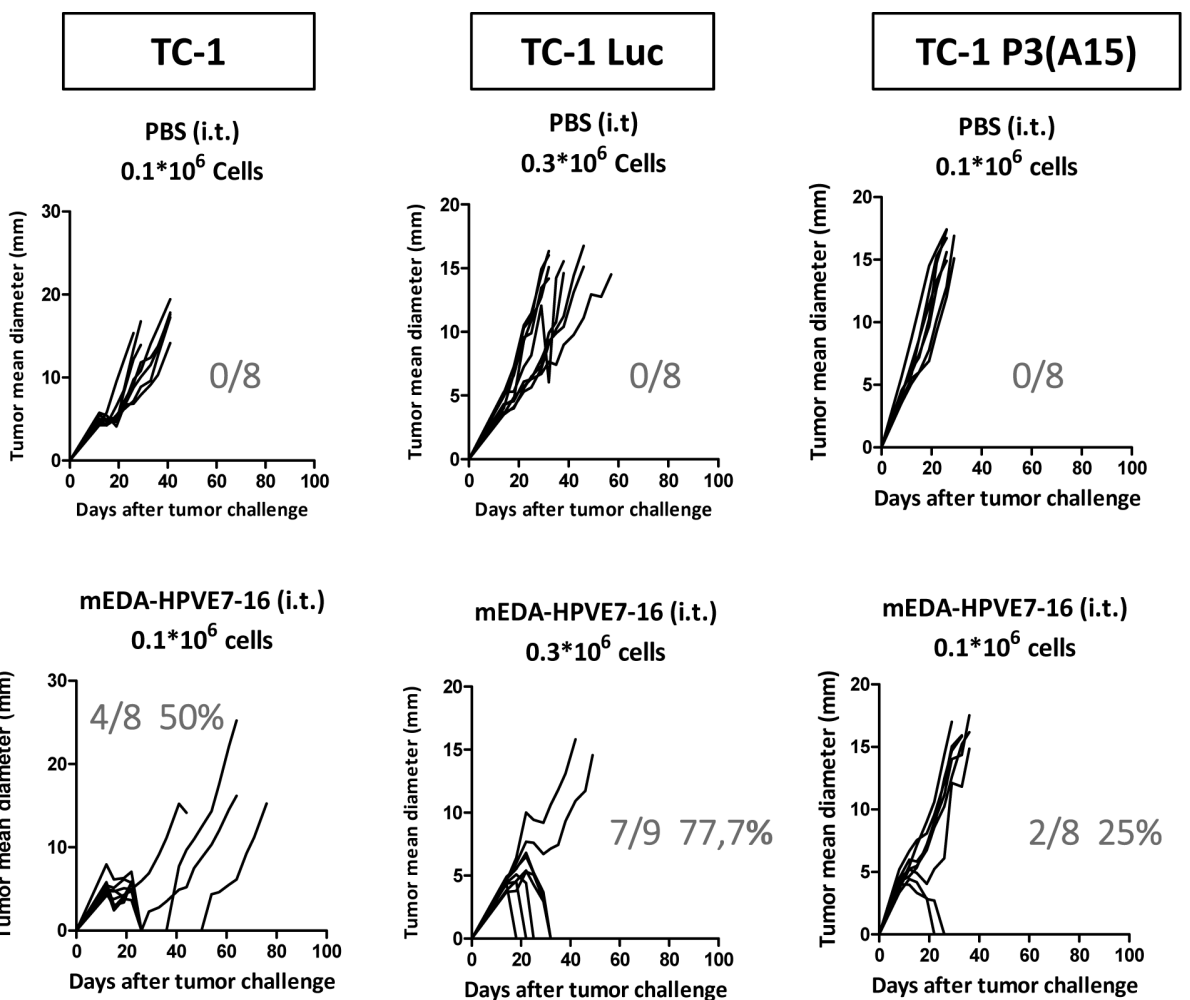

Figure 2 Therapeutic efficacy of intratumor mEDA-HPVE7-16 immunotherapy in the absence of adjuvants in different TC-1based tumor models. C57BL/6 mice were challenged subcutaneously with $1 \times 10^{5} \mathrm{TC}-1,3 \times 10^{5} \mathrm{TC}-1$ Luc or $1 \times 10^{5} \mathrm{TC}-1 \mathrm{P} 3$ (A15) tumor cells and treated as indicated ( $n=8$ per group). mEDA-HPVE7-16 protein was administered intratumorally (i.t.) at days 3 , 4, 5, 6 and 7 ( $3 \mathrm{nmols} / \mathrm{mouse} /$ day) ( $\mathrm{n}=8-9$ per group). Tumor size (average of two perpendicular diameters (mm)) was measured at regular intervals. The ratio of tumor-free mice/total mice is shown at day 90 for each treatment. Mice were sacrificed when tumor diameters reached $18 \mathrm{~mm}$ or when warranted based on the health of the animals. Results are representative of three independent experiments. PBS, phosphate-buffered saline.

effect of its combination with an adjuvant in the more difficult-to-treat TC-1 P3 (A15) tumor model. Thus, C57BL/6 mice were injected subcutaneously with $10^{5}$ TC-1 P3 (A15) cells and 7 days later, when tumor mean diameters were around $5 \mathrm{~mm}$, they were treated intratumorally with PBS; $50 \mu \mathrm{g}$ of Poly IC; 3 nmol of EDA-HPVE7 or $3 \mathrm{nmol}$ EDA-HPVE $7+50 \mu \mathrm{g}$ of Poly IC in the same mixture. A group of mice was treated subcutaneously with 3 nmol EDA-HPVE 7+50 $\mu \mathrm{g}$ of Poly IC. A second immunization was done at day 14 following the same immunization protocol for each group. Tumors from mice treated with PBS or with Poly IC alone grew progressively and mice had to be sacrificed between days 20 and 35 (figure 3 ). The protein mEDA-HPVE7-16 alone, in the absence of adjuvant, achieved tumor eradication in only two out of eight animals $(25 \%)$, whereas treatment with the combination of mEDA-HPVE7-16 and Poly IC achieved complete tumor eradication in three out of eight $(37.5 \%)$ when the vaccine was injected subcutaneously and in five out of eight $(62.5 \%)$ when the vaccine was injected intratumorally (figure 3$)(p=0.0004$ and $p=0.04$ as determined by likelihood ratio test between mice treated with EDAHPVE7 intratumorally. or subcutaneously with respect to intratumorally EDA-HPVE7 alone, and $\mathrm{p}<0.0005$ as determined by log-rank test when comparing survival curves).

\section{Therapeutic efficacy of mEDA-HPVE7-16 in combination with Poly ICLC adjuvant}

We substituted Poly IC by the stabilized Poly ICLC adjuvant (Hiltonol, Oncovir), which has proved to be 5-fold to 10-fold more resistant to hydrolysis and induced significant serum levels of IFN- $\gamma^{26}{ }^{27}$ As controls, we included the synthetic peptide $\mathrm{E} 7_{43-77}$, containing the $\mathrm{E} 7_{49-57}$ H2-Db-restricted CTL epitope with its natural flanking sequences ${ }^{28}$ and that has been proven to have therapeutic efficacy when combined with adjuvants. ${ }^{29-31}$ Thus, we included Poly ICLC as an adjuvant for mEDA-HPVE7-16 when it is administered subcutaneously, which represents a more feasible delivery route for use in patients. TC-1 P3 (A15) tumor-bearing C57BL/6 mice were treated by subcutaneous injection with: PBS; Poly IC; Poly ICLC; mEDA-HPVE7-16 alone; mEDA-HPVE7-16+Poly IC; $100 \mu \mathrm{g}$ of peptide $\mathrm{E} 7_{43-77}$ alone; $100 \mu \mathrm{g}$ of peptide $\mathrm{E} 7_{43-}$ ${ }_{77}+$ Poly ICLC or mEDA-HPVE7-16+Poly ICLC following the same schedule as in the previous experiment. No therapeutic effect was observed in mice treated with PBS, Poly IC, Poly ICLC or with peptide E $7_{43-77}$ alone, whereas mEDA-HPVE7-16 alone or the combination of $\mathrm{E} 7_{43-77}$ peptide+Poly ICLC induced tumor rejection in $12.5 \%$. In agreement with results found in figure 3 , combination of mEDA-HPVE7-16+Poly IC cured tumors in $75 \%$ of the 
A
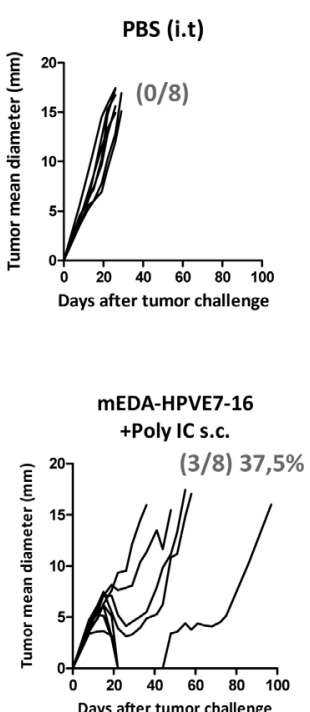
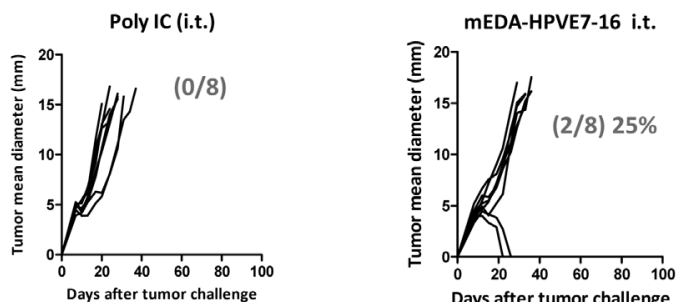

B

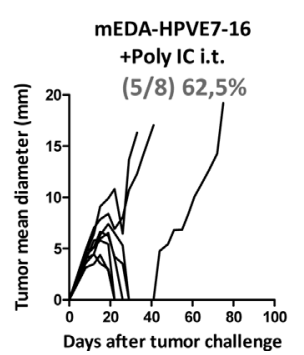

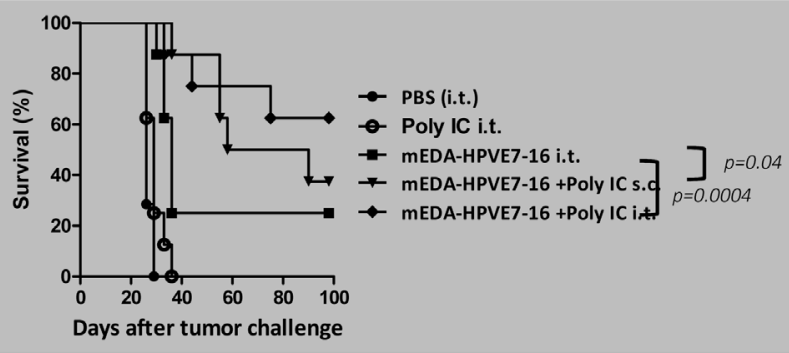

Figure 3 Therapeutic efficacy of mEDA-HPVE7-16 immunotherapy alone or in combination with polyinosinic-polycytidylic acid (Poly IC) adjuvant in TC-1 P3 (A15)-based tumor model. C57BL/6 mice were challenged subcutaneously (s.c.) with $1 \times 10^{5}$ TC-1 P3 (A15) tumor cells. Seven days later, when the tumor diameter is above $5 \mathrm{~mm}$, they were treated as indicated ( $\mathrm{n}=8$ per group). They were subsequently boosted at day 14 . Mice were treated with mEDA-HPVE7-16 protein $(3 \mathrm{nmols} / \mathrm{mouse})+$ Poly IC $(50 \mu \mathrm{g} /$ mouse) intratumorally (i.t.) or s.c. Tumor size (average of two perpendicular diameters $(\mathrm{mm})$ ) was measured at regular intervals. The ratio of tumor-free mice/total mice is shown at day 90 for each treatment. Mice were sacrificed when tumor diameters reached $18 \mathrm{~mm}$ or when warranted based on the health of the animals. Kaplan-Meier plot is depicted for each treatment. Results are representative of two independent experiments. PBS, phosphate-buffered saline.

animals. Nevertheless, combination of mEDA-HPVE7$16+$ Poly ICLC induced tumor rejection in $100 \%$ of the animals (figure $4 \mathrm{~A}, \mathrm{~B}$ ).

\section{Therapeutic efficacy of mEDA-HPVE7-16 in combination with cisplatin}

Cisplatin-based chemotherapy has been the standard of care for metastatic cervical cancer for decades. Cisplatin treatment could have a negative impact on immune cells stimulated by the vaccine and could reduce its therapeutic efficacy. In a previous report, Small $e t a l^{32}$ found that, although cisplatin administration did not prevent the induction of an effective immune response after vaccination, intraperitoneal administration of three doses of $5 \mathrm{mg} / \mathrm{kg}$ cisplatin had an effect reducing the number of peptide-specific IFN- $\gamma$-producing cells. We carried out a previous experiment to evaluate the effect of cisplatin on the immunogenicity of mEDA-HPVE7-16. Thus, mice were immunized subcutaneously with $3 \mathrm{nmol}$ mEDA-HPVE7-16 and treated intraperitoneally with $5 \mathrm{mg} / \mathrm{kg}$ cisplatin or with saline at days 0 and 3. Seven days after immunization, we evaluated the number of specific IFN- $\gamma$-producing cells in response to stimulation with peptide $\mathrm{E} 7_{49-57}$ or with irradiated TC-1 tumor cells. Although it was observed a slight increase on the immune response in mice treated with cisplatin this difference did not reach statistical significance (online supplementary figure 1). Therefore, we assessed whether cisplatin $(5 \mathrm{mg} / \mathrm{kg}$ body weight at days 5 and 8) might represent a useful adjunct therapy for use with mEDA-HPVE7-16 immunotherapy following challenge with TC-1 P3 (A15) tumor cells. As described in figure 5, intratumoral treatment with mEDA-HPVE7-16 alone was able to cure $37.5 \%$ of tumors, whereas the addition of cisplatin to the treatment regimen led to the eradication of tumors in $75 \%$ of mice $(\mathrm{p}=0.0711)$. In contrast, cisplatin alone was comparable to PBS and appeared to have little effect on tumor growth. Notably, treatment of mice with intratumoral $\mathrm{E} 7_{43-77}$ peptide and cisplatin yielded a cure rate of $25 \%$, significantly inferior effect than mEDA-HPVE7-16+cisplatin ( $25 \%$ vs $75 \%$, $\mathrm{p}=0.0127$ ) (figure 5A). Chemotherapy also improved the antitumor effect of mEDA-HPVE7-16 when the vaccine was administered by the subcutaneous route (final cure rate of $37.5 \%$ vs $0 \%$ with the vaccine alone, $\mathrm{p}<0.05$, figure $5 \mathrm{~B}$ ). Thus, although subcutaneous administration of mEDAHPVE7-16 appeared to be less efficacious when compared with intratumoral vaccination, combination with cisplatin improved the therapeutic responses in both cases.

\section{Therapeutic efficacy of a fusion protein between hEDA and HPVE7 proteins from HPV16 and HPV18 genotypes}

To advance the preclinical development of the mEDAHPVE7-16 vaccine toward clinical application in patients with HPV-related malignancies, we generated hEDAHPVE7-16, which contains the hEDA and lacks the histidine tag included in mEDA-HPVE7-16. In parallel, we attempted to improve our vaccine candidate adding the E7 protein from HPV18 to broaden the target population (bivalent vaccine) (figure 6A). We have produced (figure 6B) and tested the immunogenicity and antitumor 
A
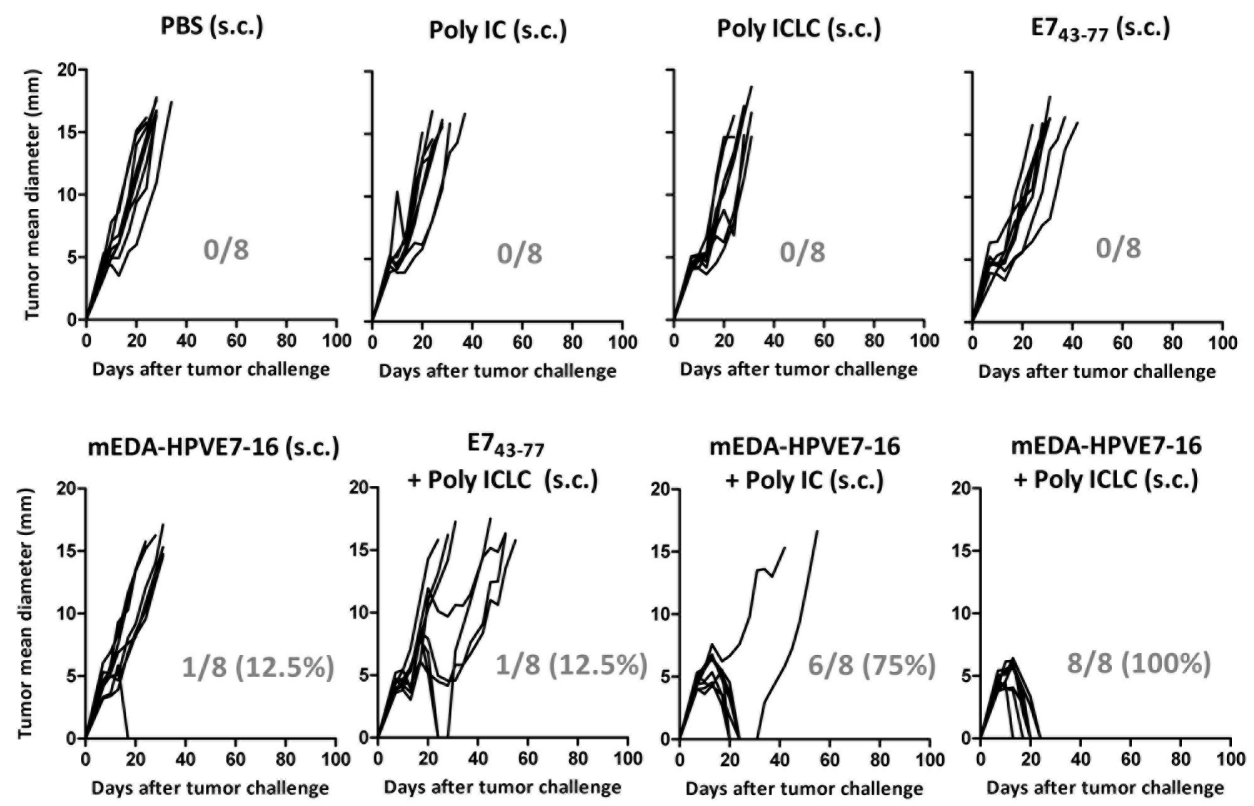

B

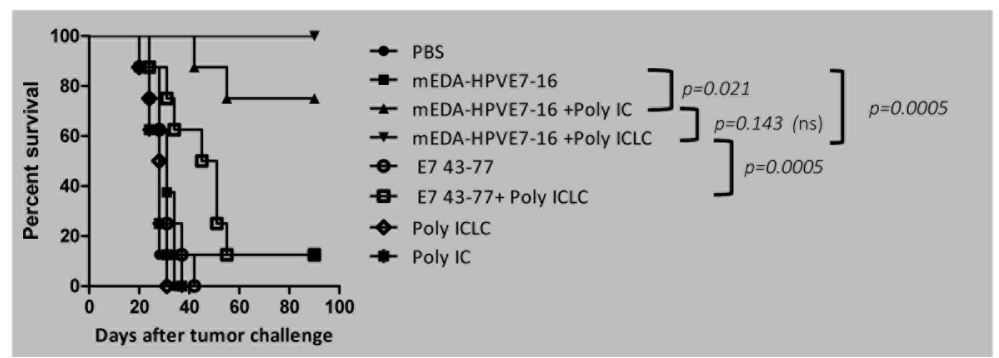

Figure 4 Therapeutic efficacy of mEDA-HPVE7-16 immunotherapy alone or in combination with Poly ICLC adjuvant in TC-1 P3 (A15)-based tumor model. C57BL/6 mice were injected subcutaneously (s.c.) with $1 \times 10^{5}$ TC-1 P3 (A15) cells. At days 7 (5 $\mathrm{mm}$ tumor diameter) and 14, mice were treated s.c. with the indicated immunogens. Proteins were administered at a dose of 3 $\mathrm{nmols} /$ mouse, whereas Poly ICLC, Poly IC and E7 ${ }_{43-77}$ peptide were delivered at $100 \mu \mathrm{g}$ per mouse. (A) Tumor size (the average of two perpendicular diameters $(\mathrm{mm})$ ) was measured at regular intervals. The ratio of tumor-free mice/total number of mice treated is shown at day 90 for each treatment. (B) Survival following treatment is depicted using a Kaplan-Meier plot. Mice were sacrificed when tumor diameters reached $18 \mathrm{~mm}$. Results are representative of three independent experiments. ns, not significant; PBS, phosphate-buffered saline.

efficacy of hEDA-HPVE7 vaccine candidates (hEDAHPVE7-16 and hEDA-HPVE7-16/18) and compared with results obtained with the mEDA-HPVE7-16 prototype vaccine (mEDA-HPVE7-16).

We first studied whether the new vaccine candidates maintained TLR4-binding capacity using HEK 293 cells stably transfected with human TRL4 (293-TLR4). It was found that mEDA-HPVE7-16 and hEDA-HPVE716/18-labeled with Alexa Fluor 488 displayed high and comparable TLR4-binding capacities $(40.2 \%$ and $36.9 \%$, respectively) (figure 6C). Surprisingly, hEDA-HPVE716-Alexa displayed a much lower level of fluorescence $(19.5 \%)$ indicating a more limited capacity to bind TLR4.

We next tested the ability of the different EDAHPVE7 proteins to induce the production of TNF- $\alpha$ by TLR4-expressing cell line THP-1 (human monocytes) and the IL-12 production by human monocyte-derived
DCs. mEDA-HPVE7-16, hEDA-HPVE7-16 and hEDAHPVE7-16-18 candidates induced production of high levels of TNF- $\alpha$ in a dose-dependent manner (figure 6D). We also observed that, while mEDA-HPVE7-16 induced low levels of IL-12, hEDA-HPVE7-16/18 and, to a lower extent, hEDA-HPVE7-16, were capable of inducing high levels of IL-12 production by human-derived DC (figure 6E).

In order to compare the relative ability of the EDAHPVE7 fusion proteins to induce HPVE7-specific T-cell responses in vivo, C57BL/6 mice were immunized subcutaneously with $3 \mathrm{nmol}$ of each of the vaccine candidates in the presence or absence of Poly IC. Also, the hEDA protein alone and the $\mathrm{E}_{43-77}$ peptide were used as controls. Ten days later, mice were sacrificed and their spleen cells were cultured in the presence or absence of $\mathrm{E}_{49-57}$ peptide. Subsequently, the number of IFN- $\gamma$-producing cells was 

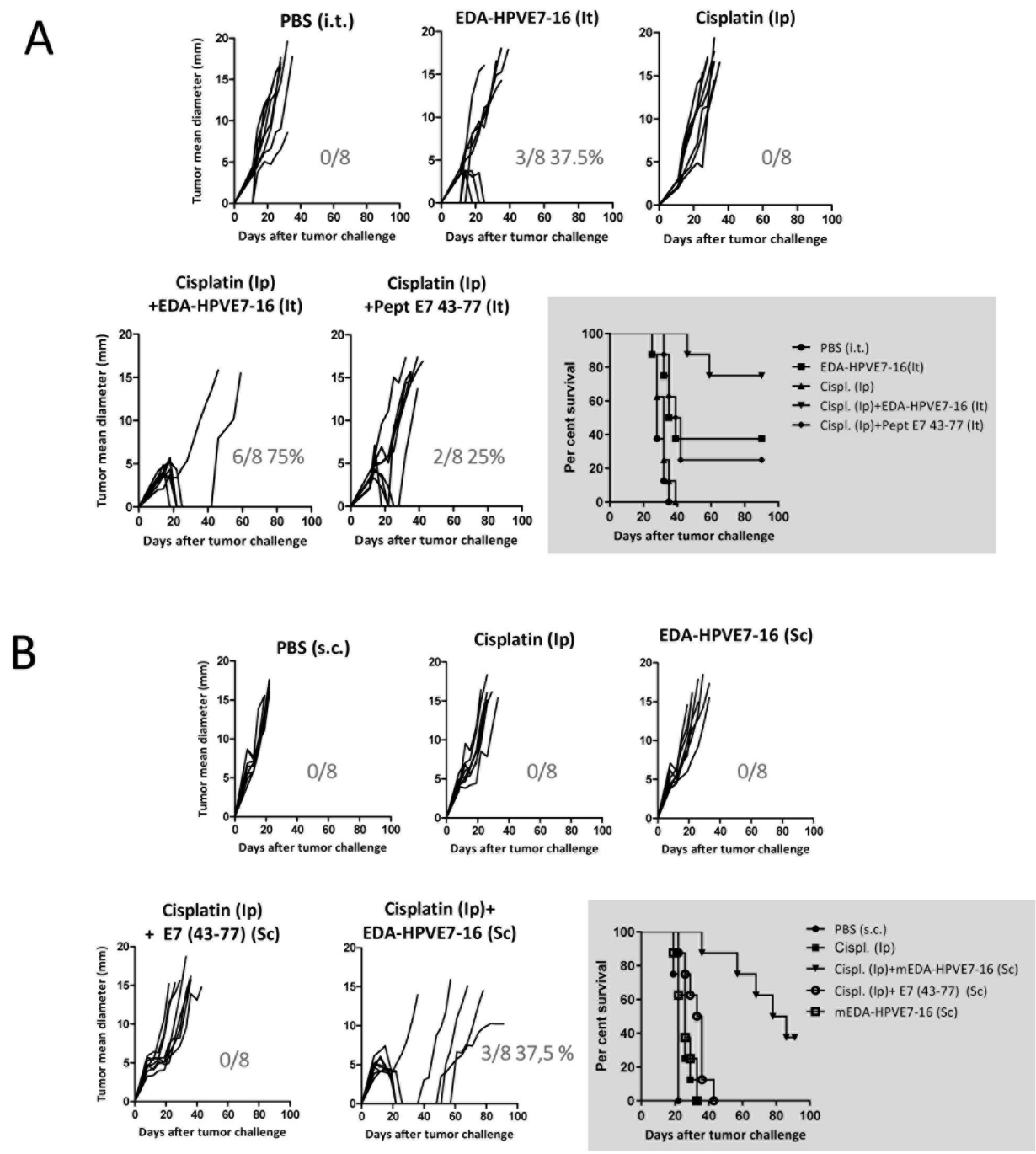

Figure 5 Therapeutic efficacy of subcutaneous (s.c.) mEDA-HPVE7-16 immunotherapy combined with cisplatin chemotherapy. C57BL/6 mice were challenged s.c. with $1 \times 10^{5} \mathrm{TC}-1$ P3 (A15) tumor cells and treated as indicated ( $\mathrm{n}=8$ per group). mEDAHPVE7-16 ( $3 \mathrm{nmol})$, mEDA ( $3 \mathrm{nmol})$, Poly IC $\left(50 \mu \mathrm{g} /\right.$ mouse) and peptide E7 ${ }_{43-77}(20 \mu \mathrm{g} / \mathrm{mouse})$ were s.c. administered at days 5,8 and 11 , whereas cisplatin ( $5 \mathrm{mg} / \mathrm{kg}$ body weight) was administered intraperitoneally (i.p.) at days 5 and 8 . (A) Tumor size (average of two perpendicular diameters $(\mathrm{mm})$ ) was measured at regular intervals. The ratio of tumor-free mice/total mice is shown at day 90 for each treatment. (B) A Kaplan-Meier plot is depicted for each treatment. Mice were sacrificed when tumor diameters reached $18 \mathrm{~mm}$ or based on the health of the individual animals. PBS, phosphate-buffered saline.

measured by ELISPOT. Mice that did not receive Poly IC had low numbers of $\mathrm{E}_{49-57}$-specific IFN- $\gamma$-producing cells in comparison to mice treated with Poly IC (figure 6F). Vaccination with $\mathrm{E} 7_{43-77}$ alone or plus Poly IC did not yield an $\mathrm{E} 7_{49-57}$-specific IFN- $\gamma$ response, further supporting the immunostimulatory capacity of EDA. In contrast, hEDA-HPVE7-16/18 combined with Poly IC induced strong CTL responses against the $\mathrm{E}_{49-57}$ peptide, with similar efficacy to that of the mEDA-HPVE7-16 prototype vaccine. Once demonstrated similar immunogenicity between mEDA-HPVE7-16 and hEDA-HPVE7-16/18, we conducted the same assay in the presence of the stabilized version Poly ICLC, and tested the immune response against $\mathrm{CD}^{+}$T-cell epitopes from HPV16 and HPV 18 genotypes. Overall, combination of mEDA-HPVE7-16 and hEDA-HPVE7-16/18 proteins with Poly ICLC led to a similar E7 ${ }_{49-57}$-specific immune response as with Poly IC.
However, an increased number of IFN- $\gamma$-producing cells were seen when using Poly ICLC (figure 6G). Importantly, vaccination with hEDA-HPVE7-16/18 was able to induce immune responses specific for both HPV16 and HPV18 genotypes (figure 6G). Indeed, mice immunized with hEDA-HPVE7-16/18 elicited IFN- $\gamma$-producing cells specific for HPV18 E7 $7_{7-15}$ and $\mathrm{E} 7_{86-94}$ epitopes, not elicited by mEDA-HPVE7-16.

We then evaluated the therapeutic efficacy of hEDAHPVE7-16/18 vaccine candidate in the TC-1 P3 (A15) tumor model. C57BL/ 6 mice were injected subcutaneously with $1 \times 10^{5}$ TC-1 P3 (A15) cells and at days 7 and 14 were treated subcutaneously with $3 \mathrm{nmol}$ of hEDAHPVE7-16/18+50 $\mu \mathrm{g}$ of Poly ICLC or with PBS. We found that tumors were eradicated in $100 \%$ of animals after vaccination with hEDA-HPVE7-16/18+Poly ICLC 
A

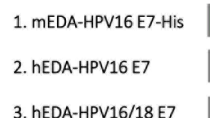

3. hEDA-HPV16/18 E
C
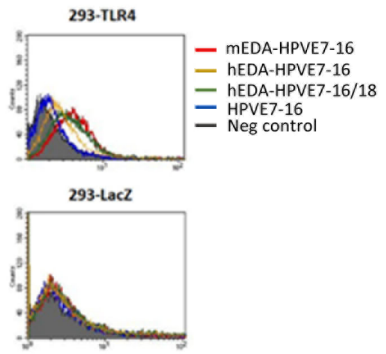

D

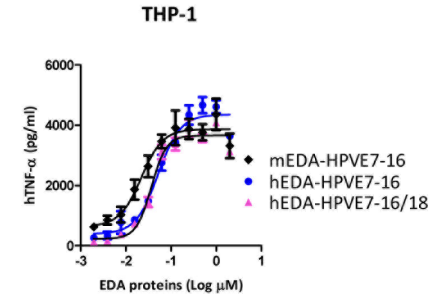

E
1234
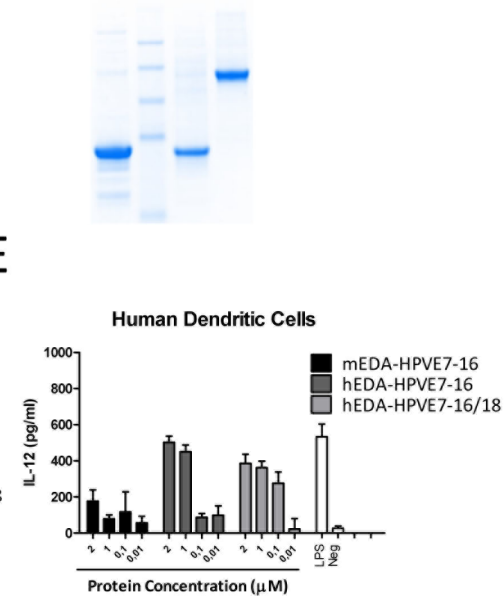

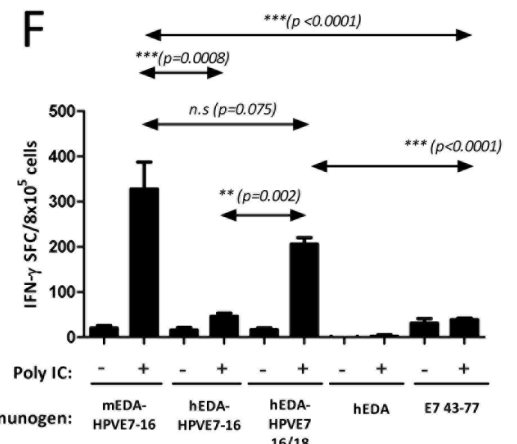

G

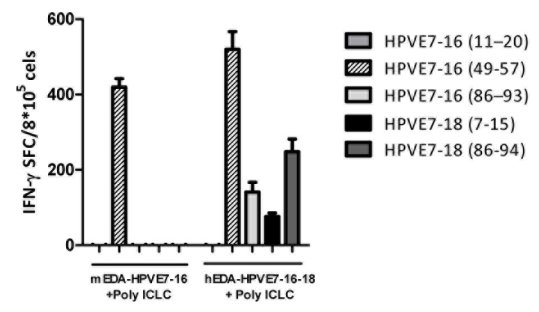

$\mathrm{H}$
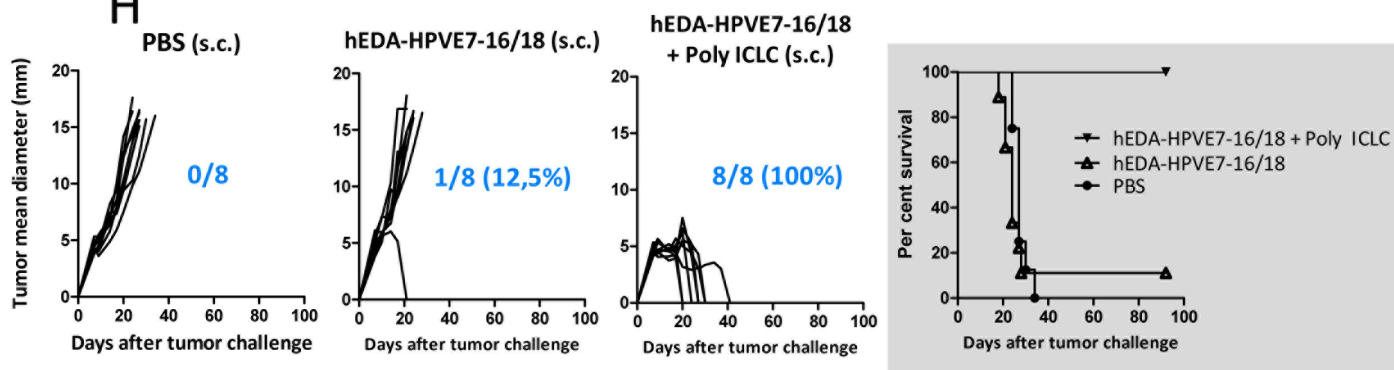

Figure 6 In vivo induction of cellular immune responses against HPVE7 following immunization with EDA-HPVE7 vaccine candidates. (A) Schematic representation of the candidate fusion proteins. (B) Coomassie staining of the produced proteins (lane 1: mEDA-HPVE7-16; lane 2: molecular weight marker; lane 3: hEDA-HPVE7-16; lane 4: hEDA-HPVE7-16/18). (C) Binding of the fusion proteins to 293-toll-like receptor 4 (TLR4) and 293-LacZ expressing cells, measured by flow cytometry. (D) Tumor necrosis factor (TNF)- $\alpha$ production by THP-1 cells in response to stimulation with the indicated proteins. (E) Interleukin (IL)-12 production by human monocyte-derived dendritic cell (DC) in response to protein stimulation. (F) Number of interferon (IFN)$\gamma$-producing cells specific for peptide $\mathrm{E}_{49-57}$ peptide in $\mathrm{C} 57 \mathrm{BL} / 6$ mice previously immunized with the indicated protein \pm Poly IC. (G) Number of IFN- $\gamma$-producing cells specific for peptides from HPV16 and HPV18 genotypes in C57BL/6 mice previously immunized with hEDA-HPVE7-16/18 protein+Poly ICLC. (H) Antitumor efficacy of subcutaneous immunization with PBS, hEDA-HPVE7-16/18 alone or hEDA-HPVE7-16/18+Poly ICLC in C57BL/6 mice bearing TC-1 P3 (A15) tumors. Tumor size was measured at regular intervals. The ratio of tumor-free mice/total number of mice treated is shown at day 90 for each treatment. Survival following treatment is depicted using a Kaplan-Meier plot. Results are representative of two independent experiments. n.s., not significant; PBS, phosphate-buffered saline.

(figure 6H). Treatment of mice with hEDA-HPVE7-16/18 in combination with cisplatin was also able to cure five out of eight $(62.5 \%)$ animals (online supplementary figure 2). These results suggest that the newly developed bivalent vaccine hEDA-HPVE7-16/18 could generate clinical benefit in patients with cervical cancer in combination with the currently applied treatments regimens when administered with Poly ICLC. In a next step, we evaluated the therapeutic efficacy of hEDA-HPVE7-16/18+Poly ICLC combination in an orthotopic genital tumor model. 


\begin{tabular}{ll}
\hline Table 1 & ISA synthetic long peptides (13 SLP) \\
\hline Peptide & Sequence \\
\hline E6 1-32 & MHQKRTAMFQDPQERPRKLPQLCTELQTTIHD \\
\hline E6 19-50 & LPQLCTELQTTIHDIILECVYCKQQLLRREVY \\
E6 41-65 & KQQLLRREVYDFAFRDLCIVYRDGN \\
\hline E6 55-80 & RDLCIVYRDGNPYAVCDKCLKFYSKI \\
E6 71-95 & DKCLKFYSKISEYRHYCYSLYGTTL \\
E6 85-109 & HYCYSLYGTTLEQQYNKPLCDLLIR \\
E6 91-120 & YGTTLEQYNKPLCDLLIRCINCQKPLCPEEK \\
E6 109-140 & RCINCQKPLCPEEKQRHLDKKQRFHNIRGRWT \\
E6 127-158 & DKKQRFHNIRGRWTGRCMSCCRSSRTRRETQL \\
\hline E7 1-35 & MHGDTPTLHEYMLDLQPETTDLYCYEQLNDSSEEE \\
E7 22-56 & LYCYEQLNDSSEEEDEIDGPAGQAEPDRAHYNIVT \\
\hline E7 43-77 & GQAEPDRAHYNIVTFCCKCDSTLRLCVQSTHVDIR \\
\hline E7 64-9 & TLRLCVQSTHVDIRTLEDLLMGTLGIVCPICSQK \\
\hline
\end{tabular}

\section{Evaluation of EDA-HPVE7 vaccine in a murine orthotopic genital cancer model}

The therapeutic efficacy of these vaccines was also tested in an orthotopic tumor model which represents a more realistic and predictive model for evaluation of cervical cancer immunotherapies. ${ }^{24}$ In this model, luciferaseexpressing TC-1 cells are directly instilled in the vagina, resulting in tumors that require the homing of vaccineinduced immune responses to the genital mucosa. Genital tumors were established in the mice as described in methods section and monitored by in vivo bioluminescence over time. We then evaluated the capacity of the hEDA-HPVE7-16/18 vaccine to induce antitumor effector E7-specific $\mathrm{CD}^{+}$T-cell responses, compared with an antigen formulation based on 13 synthetic long peptides (SLP) (table 1) emulsified in IFA/Montanide. This peptide-combined formulation is similar to that used in the ISA peptide-based vaccine (ISA SLP), which has demonstrated convincing therapeutic effects. ${ }^{33}{ }^{34}$ We also added a control group consisting of the synthetic peptides $\mathrm{E} 7_{1-35}$ and $\mathrm{E} 7_{43-77}+$ Poly ICLC which includes the sequence of the SLP E7 ${ }_{43-77}$, already demonstrated to eradicate established HPV16 expressing tumors. ${ }^{3135}$ Thus, group of mice bearing genital tumors were immunized subcutaneously at day 1 and day 8 with (i) hEDA-HPVE7-16/18 (3 nmols)+Poly ICLC $(50 \mu \mathrm{g})$, (ii) with peptides $\mathrm{E} 7_{1-35}$ and $\mathrm{E}_{43-77}(50 \mu \mathrm{g} \times 2)+$ Poly ICLC $(50 \mu \mathrm{g})$ or (iii) with 13 SLP peptides $(13 \times 50 \mu \mathrm{g})+\mathrm{IFA} /$ Montanide.

Vaccine-specific immune reactions were evaluated by bleeding the mice 7 days after the first and 6 days after the second vaccination (postboost) and performing ELISPOT assays on the purified PBMCs. E7-specific IFN- $\gamma$-secreting $\mathrm{CD}^{+} \mathrm{T}$ cells could be detected in the PBMC of the majority of the treated mice after the first vaccination (figure 7A). Following boosting, a significant improvement of immune reaction was observed in mice vaccinated with hEDA-HPVE7-16/18+PolyICLC $(185 \pm 50)$. In addition, the response in the $\mathrm{E} 7_{1-35}$ and $\mathrm{E} 7_{43-77}+$ Poly ICLC group was augmented by boosting $(94 \pm 20)$. In contrast, boosting vaccination with the 13 SLP peptides+Montanide did not have a strong effect $(29 \pm 8)$. As expected, unvaccinated mice harboring day 21 tumors exhibited a relatively small, but detectable, immune response $(5 \pm 3)$. But more importantly, hEDA-HPVE7-16/18+Poly ICLC induced full regression of $100 \%$ of the orthotopic tumors and was more efficacious than the 13 SLP peptides+Montanide $(\mathrm{p}<0.01)$ or than $\mathrm{E} 7_{1-35}$ and $\mathrm{E} 7_{43-77}+$ Poly ICLC $(\mathrm{p}=0.067)$ (figure $7 \mathrm{~B}, \mathrm{C})$.

\section{DISCUSSION}

Vaccination strategies based on the in vivo targeting of antigens to DCs have demonstrated to induce specific T-cell immunity against tumors and infectious agents. ${ }^{36}$ As part of the preclinical development of an EDA-HPVE7based therapeutic vaccine against HPV-related cervical carcinoma, we have worked to adapt the mEDA-HPVE7-16 fusion protein, which was used in initial efficacy experiments in mice, for use in human clinical studies.

We have confirmed the antitumor efficacy of mEDAHPVE7-16 vaccine in the absence of adjuvants eliciting a robust cellular immune response. However, the antitumoral efficacy is significantly reduced when the TC-1 P3 (A15) variant system, with a reported downregulation of MHC expression, was used. Therefore, we evaluated possible adjunct therapies that might improve the efficacy of mEDA-HPVE7-16 therapeutic HPV vaccine.

Cisplatin-based chemotherapy has been the standard of care for metastatic cervical cancer for decades. It is a platinum-containing anticancer drug, which binds to and crosslinks DNA, ultimately triggering cell death (apoptosis). ${ }^{37}$ Unfortunately, only approximately one-third of patients with cervical cancer respond to cisplatin-based chemotherapy, with responses typically lasting fewer than 12 months. ${ }^{38}$ It has been suggested that cisplatin treatment can promote the release of pro-inflammatory substances from dying tumor cells ${ }^{39} 40$ and convert the tumor microenvironment into a more permissive site with regard to adaptive immune responses. ${ }^{41}$ Thus, cisplatin co-administration might provide a mechanism to augment responses against tumor antigens during vaccination. ${ }^{3542} 43$ However, it has also been reported that cisplatin fails to induce immunogenic tumor cell death that would allow to stimulate an anticancer immune response. ${ }^{44}$ In our experiments, the therapeutic efficacy of mEDA-HPVE7-16 was significantly improved when it was combined with cisplatin. In this regard, intratumor administration of EDA-HPVE7 in combination with cisplatin (intraperitoneal) was found to be more efficacious than subcutaneous administration in the TC-1 P3 (A15) tumor model. It could be speculated that reduced capacity of cisplatin to induce immunogenic cell death could be restored by intratumoral administration of EDA that might provide a pro-inflammatory signal to DC and improve their maturation in situ. Nevertheless, also subcutaneous vaccination in combination with cisplatin 
A
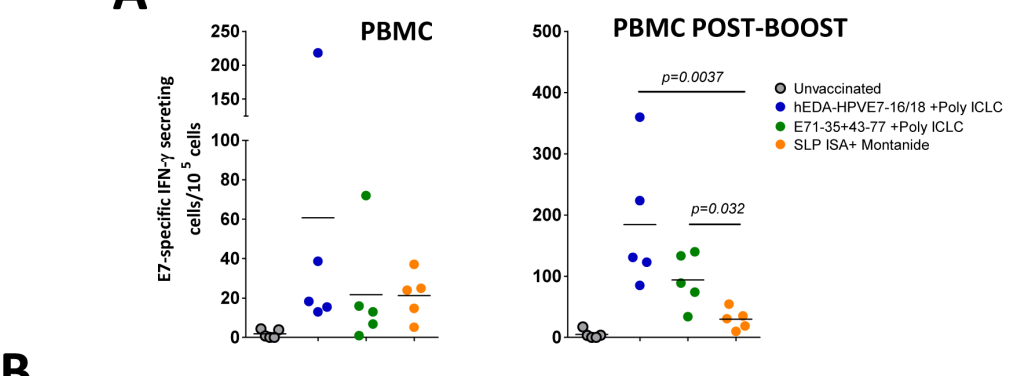

B
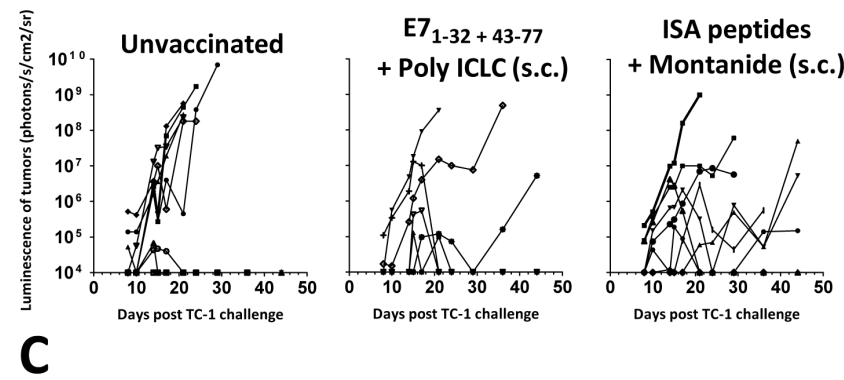

hEDA-HPVE7-16/18

+ Poly ICLC (s.c.)
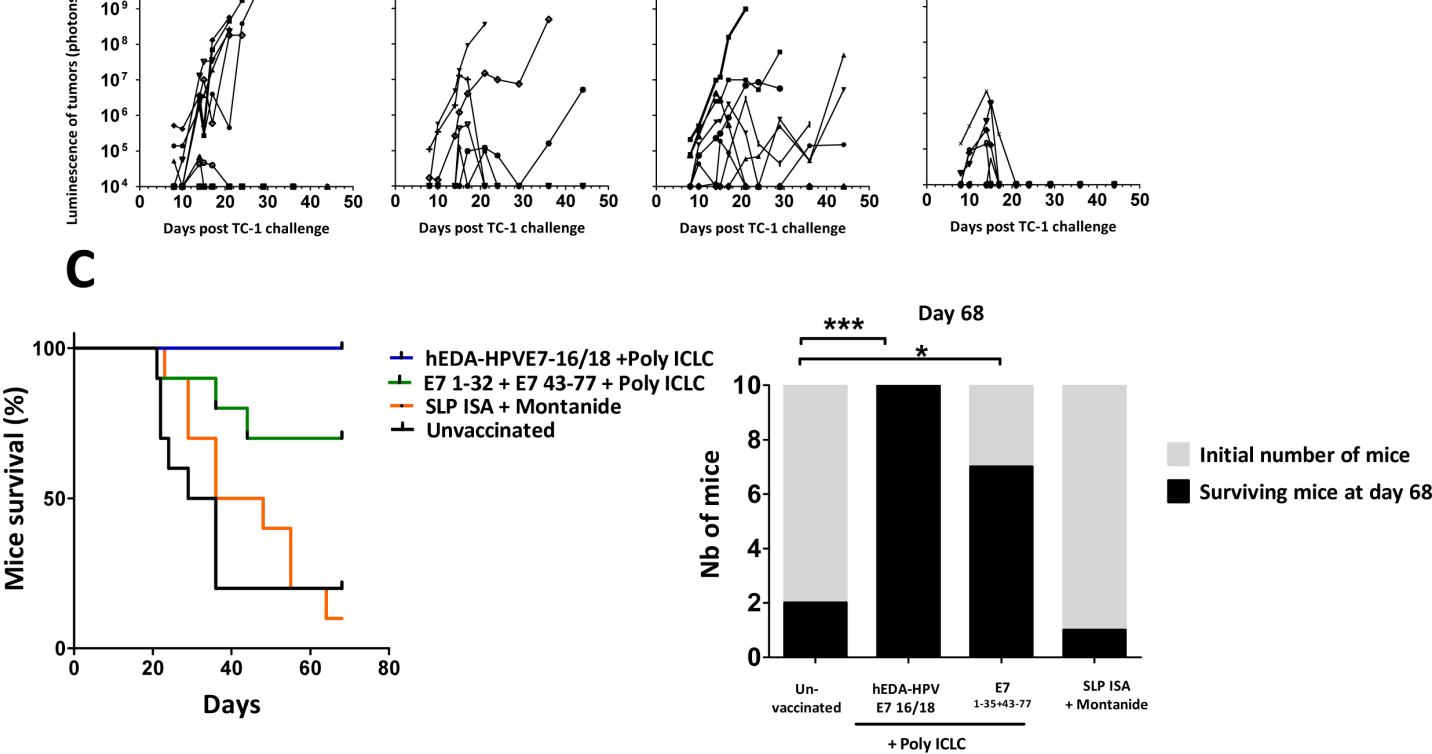

Figure 7 Evaluation of hEDA-HPVE7-16/18 vaccine in a murine orthotopic genital cancer model. Immune responses to the vaccines in naïve mice (A, B) and in mice bearing cervical tumors (C). (A) C57BL/6 mice were immunized by the subcutaneous route with the indicated immunogen and 7 days later, $E 7_{49-57}$-specific interferon (IFN)- $\gamma$-secreting $T$ cells in the indicated organs measured by ELISPOT ( $\mathrm{n}=3-4$ mice per group). (B) Percentage of E7 ${ }_{49-57}$-specific $T$ cells on total CD8 ${ }^{+} T$ cells was measured by tetramer staining ( $n=3-6$ mice per group). (C) Mice received intravaginally TC-1-luc cells at day 1 and were vaccinated at days 9 and 16. E7-specific IFN- $\gamma$-secreting cells were measured in the peripheral blood mononuclear cells (PBMCs) 7 days after the first and 6 days after the second vaccination ( $n=5$ mice per group). (D) Tumor follow-up. Change in tumor bioluminescence over time is displayed for each mouse until their sacrifice (data shown by vaccination group). (E) Survival curves. Survival of the different vaccinated groups. Survival of mice vaccinated with hEDA-HPVE7-16/18 was higher than survival of mice treated with SLP ISA/Montanide or E7 1-32+E7 43-77+Poly ICLC ( $<0.0001$ and $p=0.067$, respectively using log-rank test). The initial number of mice (gray) and the number of mice surviving at day 68 (black) are also shown. Significant differences were detected using the Fisher's exact test: ${ }^{\star} \mathrm{p}<0.05,{ }^{\star \star *} \mathrm{p}<0.001$. SLP, synthetic long peptides.

was able to eliminate tumors efficiently in the TC-1 P3 (A15) model, suggesting that our candidate vaccine could generate clinical benefit in combination with the currently applied chemotherapy.

We then explored whether the combination of mEDAHPVE7-16 with an adjuvant such as the TLR3 ligand poly-IC could improve CTL priming against E7. In this TC-1 P3 (A15) tumor model, the use of Poly IC, and specially its stabilized version Poly ICLC (Hiltonol) as an adjuvant, significantly improved the antitumor efficacy of the vaccine, achieving $100 \%$ of tumor rejection. These results prompted us to continue our studies with theTLR3 ligand poly-ICLC.

As part of the preclinical development of an EDAHPVE7-based vaccine, we adapted mEDA-HPVE7-16 for its use in humans. Thus, mEDA was substituted by hEDA and the E7 from HPV18 was also incorporated to generate the fusion protein hEDA-HPVE7-16/18 to display a broader target population (20\% increase), which mirrors the approach used by existing prophylactic vaccines against HPV. Our in vitro experiments confirmed the TLR4binding capacity of hEDA-HPVE7-16/18 vaccine candidate. The in vitro findings correlated with the in vivo experiments, which measured the induction of HPVE7specific CTL immune responses and therapeutic efficacy in the TC-1 P3 (A15) tumor model. In this regard, hEDAHPVE7-16/18 was shown to reproduce the immunostimulatory properties of mEDA-HPVE7-16. But importantly, hEDA-HPVE7-16/18 was able to induce specific T-cell responses against epitopes from the HPVE7 18 variant, 
confirming the broader spectrum of the newly developed bivalent vaccine.

HPV genotype distribution analyzes in patients with invasive cervical cancer indicate that HPV 16 and HPV 18 are the two most common types worldwide, which together are responsible for $>70 \%$ of all cervical cancers. ${ }^{3}{ }^{45}$ Notably, HPV 18-related cervical carcinomas, particularly those diagnosed at an early stage, have been associated with a poor prognosis and a higher risk of relapse, ${ }^{464}$ stressing the need to develop a therapeutic vaccine for both HPV16 and HPV18 genotypes. Taken together, incorporation of the HPV18 E7 sequence into hEDA-HPVE7-16 produced a vaccine candidate that yielded high immunogenicity (hEDA-HPVE7-16/18), especially when combined with Poly ICLC.

We compared the hEDA-HPVE7-16/18 vaccine candidate (hEDA-HPVE7-16/18+Poly ICLC) with a previously developed vaccine in an orthotopic model of cervical carcinoma. Immune response induced with the 13 SLP peptides+Montanide in healthy mice was almost undetectable in spleen, PBMC or in the cervical mucosa. However, subcutaneous immunization with hEDA-HPVE7-16/18 or E7 ${ }_{1-35}$ and E7 ${ }_{43-77}$ (both adjuvanted with Poly ICLC) induced clear E7-specific immune responses in the spleen and PBMCs (online supplementary figure 3). Interestingly, E7-specific immune responses induced by the vaccines were higher in mice bearing genital tumors, the hEDAHPVE7-16/18 vaccine being the more immunogenic after boosting when compared with unvaccinated mice. These results might suggest that the presence of genital tumors contributed somehow to the observed immune responses (in PBMCs) following hEDA-HPVE7-16/18 vaccination. Notably, the high E7-specific $\mathrm{CD}^{+}$T-cell responses observed in PBMCs from hEDA-HPVE7-16/18 vaccinated mice were associated with regression of genital tumors. As a result, the hEDA-HPVE7-16/18 vaccine produced a $100 \%$ survival rate. Tumor rejection in this unique immunocompetent animal model of genital HPV-expressing tumors, which retains several immunological features of naturally occurring HPV tumors ${ }^{18}$ requires that vaccineinduced immune responses traffic to the GM and overcome local immunosuppression to allow tumor control. Future experiments are needed to verify the traffic of antitumor $\mathrm{T}$ cells induced by the vaccine to the genital mucosa and overcome local immunosuppression to allow tumor control. This is probably similar to what is necessary to induce regression of HPV lesions in patients, and thus these results may better predict the therapeutic efficacy of our candidate vaccination in patients harboring high-grade genital lesions.

In summary, we have generated a bivalent HPV vaccine based on a fusion protein between hEDA and the E7 proteins from HPV16 and HPV18 genotypes. This fusion protein hEDA-HPVE7-16/18 retains the TLR4-binding capacity and pro-inflamatory activities of mEDA and induced strong anti-E7 immune responses in vivo. Vaccination with hEDA-HPVE7-16/18 combined with cisplatin or with Poly ICLC have a strong therapeutic potential in relevant murine models of cervical carcinoma. Our results suggest that this therapeutic vaccine approach is promising for the treatment of cervical tumors that do not respond to current immunotherapies.

\section{Author affiliations}

${ }^{1}$ Formune, Pamplona, Navarra, Spain

2Programa de Inmunología e Inmunoterapia, Centro de Investigación Médica Aplicada, University of Navarra, IdisNA, Pamplona, Navarra, Spain

${ }^{3}$ Department of Urology, Centre Hospitalier Universitaire Vaudois (CHUV), Lausanne, Switzerland

${ }^{4}$ Oncology, Centre Hospitalier Universitaire Vaudois Département d'oncologie CHUVUNIL, Lausanne, Switzerland

${ }^{5}$ Departamento de Estructura de Macromoléculas, Centro Nacional de Biotecnología (CNB-CSIC), Madrid, Spain

Twitter Pedro J Romero @JITCancer and Juan José Lasarte @jose_lasarte

Acknowledgements The authors would like to thank Elena Ciordia and Eneko Elizalde for excellent animal care and the Blood Bank of Navarra (Biobanco, IDISNA) for their collaboration and Dr FX Bosch for helpful discussion. The authors would also like to thank Dr Andres Salazar for providing Poly ICLC and for helpful discussion.

Contributors LA, DN-H, PJR, JLC, TZ and JL designed and analyzed in vitro and in vivo experiments. LA, IE, VB, TG, TL, NC, LV, SD-P, DN-H, SH-S, PS, MJR and $\mathrm{JL}$ carried out in vitro and/or in vivo experiments. LA, TG, TZ and JL wrote the manuscript. All authors read, revised and approved the final manuscript.

Funding The study was supported by grants from Ministerio de Economía y Competitividad (Retos colaboración, RTC-2014-1615-1) and Ministerio de Educación y Ciencia (SAF2016-78568-R and PID2019-108989RB-I00 to JJL), Fundación Ramón Areces, Gobierno de Navarra Industria (0011-1411-2019000079; Proyecto DESCARTHeS) and Fundación Bancaria La Caixa-Hepacare Project. Teresa Lozano is recipient of a Juan de la Cierva grant (IJCl-2017-34204). PR was supported in part by the SNSF grant Sinergia CRSII3_160708.

Competing interests Formune holds a patent for the use of peptides described in this work.

\section{Patient consent for publication Not required.}

Ethics approval Ethics approval and consent to participate. All experimental procedures were carried out in compliance with the international guidelines required for experimentation with animals. The Ethical Committee of the University of Navarra approved the experiments (Refs: 119-10 and 2016.118).

Provenance and peer review Not commissioned; externally peer reviewed.

Data availability statement All data relevant to the study are included in the article or uploaded as supplementary information. All data generated or analyzed during this study are included in this published article (and its additional files).

Open access This is an open access article distributed in accordance with the Creative Commons Attribution Non Commercial (CC BY-NC 4.0) license, which permits others to distribute, remix, adapt, build upon this work non-commercially, and license their derivative works on different terms, provided the original work is properly cited, appropriate credit is given, any changes made indicated, and the use is non-commercial. See http://creativecommons.org/licenses/by-nc/4.0/.

\section{ORCID iDs}

Pablo Sarobe http://orcid.org/0000-0003-0503-7905

Juan José Lasarte http://orcid.org/0000-0003-1641-3881

\section{REFERENCES}

1 Bosch FX, Lorincz A, Muñoz N, et al. The causal relation between human papillomavirus and cervical cancer. J Clin Pathol 2002;55:244-65

2 Joura EA, Ault KA, Bosch FX, et al. Attribution of 12 high-risk human papillomavirus genotypes to infection and cervical disease. Cancer Epidemiol Biomarkers Prev 2014;23:1997-2008.

3 de Sanjose S, Quint WG, Alemany L, et al. Human papillomavirus genotype attribution in invasive cervical cancer: a retrospective cross-sectional worldwide study. Lancet Oncol 2010;11:1048-56. 
4 Garland SM. Can cervical cancer be eradicated by prophylactic HPV vaccination? challenges to vaccine implementation. Indian J Med Res 2009;130:311-21.

5 Höpfl R, Heim K, Christensen N, et al. Spontaneous regression of $\mathrm{CIN}$ and delayed-type hypersensitivity to HPV-16 oncoprotein E7. Lancet 2000;356:1985-6.

6 Figdor CG, de Vries IJM, Lesterhuis WJ, et al. Dendritic cell immunotherapy: mapping the way. Nat Med 2004;10:475-80.

7 Brandão JG, Scheper RJ, Lougheed SM, et al. CD40-targeted adenoviral gene transfer to dendritic cells through the use of a novel bispecific single-chain Fv antibody enhances cytotoxic $\mathrm{T}$ cell activation. Vaccine 2003;21:2268-72.

8 Delneste Y, Magistrelli G, Gauchat J, et al. Involvement of LOX-1 in dendritic cell-mediated antigen cross-presentation. Immunity 2002;17:353-62.

9 Guermonprez P, Fayolle C, Rojas M-J, et al. In vivo receptormediated delivery of a recombinant invasive bacterial toxoid to CD11c + CD8 alpha -CD11bhigh dendritic cells. Eur J Immunol 2002;32:3071-81.

10 Hart JP, Gunn MD, Pizzo SV. A CD91-positive subset of CD11C+ blood dendritic cells: characterization of the APC that functions to enhance adaptive immune responses against CD91-targeted antigens. J Immunol 2004:172:70-8.

11 Hawiger D, Inaba K, Dorsett Y, et al. Dendritic cells induce peripheral T cell unresponsiveness under steady state conditions in vivo. J Exp Med 2001;194:769-80.

12 Kretz-Rommel A, Qin F, Dakappagari N, et al. In vivo targeting of antigens to human dendritic cells through DC-SIGN elicits stimulatory immune responses and inhibits tumor growth in grafted mouse models. J Immunother 2007;30:715-26.

13 Steinman RM, Nussenzweig MC. Avoiding horror autotoxicus: the importance of dendritic cells in peripheral T cell tolerance. Proc Natl Acad Sci U S A 2002;99:351-8.

14 Lasarte JJ, Casares N, Gorraiz M, et al. The extra domain A from fibronectin targets antigens to TLR4-expressing cells and induces cytotoxic T cell responses in vivo. J Immunol 2007;178:748-56.

15 Mansilla C, Berraondo P, Durantez M, et al. Eradication of large tumors expressing human papillomavirus E7 protein by therapeutic vaccination with $\mathrm{E} 7$ fused to the extra domain $\mathrm{A}$ from fibronectin. Int J Cancer 2012;131:641-51.

16 Mansilla C, Gorraiz M, Martinez M, et al. Immunization against hepatitis $C$ virus with a fusion protein containing the extra domain A from fibronectin and the hepatitis C virus NS3 protein. $J$ Hepatol 2009;51:520-7.

17 Román BS, Garrido V, Muñoz P-M, et al. The extradomain a of fibronectin enhances the efficacy of lipopolysaccharide defective Salmonella bacterins as vaccines in mice. Vet Res 2012:43:31.

18 Decrausaz L, Gonçalves A-R, Domingos-Pereira S, et al. A novel mucosal orthotopic murine model of human papillomavirusassociated genital cancers. Int J Cancer 2011;128:2105-13

19 Lin KY, Guarnieri FG, Staveley-O'Carroll KF, et al. Treatment of established tumors with a novel vaccine that enhances major histocompatibility class II presentation of tumor antigen. Cancer Res 1996;56:21-6.

20 Kim JW, Hung C-F, Juang J, et al. Comparison of HPV DNA vaccines employing intracellular targeting strategies. Gene Ther 2004;11:1011-8.

21 Chiappi M, Conesa JJ, Pereiro E, et al. Cryo-soft X-ray tomography as a quantitative three-dimensional tool to model nanoparticle:cell interaction. J Nanobiotechnology 2016;14:15.

22 Brossard C, Feuillet V, Schmitt A, et al. Multifocal structure of the T cell - dendritic cell synapse. Eur J Immunol 2005;35:1741-53.

23 Revaz V, Debonneville A, Bobst M, et al. Monitoring of vaccinespecific gamma interferon induction in genital mucosa of mice by real-time reverse transcription-PCR. Clin Vaccine Immunol 2008;15:757-64.

24 Domingos-Pereira S, Decrausaz L, Derré L, et al. Intravaginal TLR agonists increase local vaccine-specific CD8 T cells and human papillomavirus-associated genital-tumor regression in mice. Mucosal Immunol 2013;6:393-404.

25 Decrausaz L, Domingos-Pereira S, Duc M, et al. Parenteral is more efficient than mucosal immunization to induce regression of human papillomavirus-associated genital tumors. Int $J$ Cancer 2011;129:762-72.
26 Levine AS, Sivulich M, Wiernik PH, et al. Initial clinical trials in cancer patients of polyriboinosinic-polyribocytidylic acid stabilized with poly-L-lysine, in carboxymethylcellulose [poly(ICLC)], a highly effective interferon inducer. Cancer Res 1979;39:1645-50.

27 Levy HB, Baer G, Baron S, et al. A modified polyriboinosinicpolyribocytidylic acid complex that induces interferon in primates. $J$ Infect Dis 1975;132:434-9.

28 Feltkamp MC, Smits HL, Vierboom MP, et al. Vaccination with cytotoxic T lymphocyte epitope-containing peptide protects against a tumor induced by human papillomavirus type 16-transformed cells. Eur J Immunol 1993;23:2242-9.

29 Rahimian S, Fransen MF, Kleinovink JW, et al. Polymeric nanoparticles for co-delivery of synthetic long peptide antigen and poly IC as therapeutic cancer vaccine formulation. $J$ Control Release 2015;203:16-22.

30 Wu C-Y, Monie A, Pang X, et al. Improving therapeutic HPV peptidebased vaccine potency by enhancing CD4+ Thelp and dendritic cell activation. J Biomed Sci 2010;17:88.

31 Zwaveling S, Ferreira Mota SC, Nouta J, et al. Established human papillomavirus type 16-expressing tumors are effectively eradicated following vaccination with long peptides. J Immunol 2002:169:350-8.

32 Small LA, Da Silva DM, de Visser KE, et al. A murine model for the effects of pelvic radiation and cisplatin chemotherapy on human papillomavirus vaccine efficacy. Clin Cancer Res 2001;7:876s-81.

33 Kenter GG, Welters MJP, Valentijn ARPM, et al. Vaccination against HPV-16 oncoproteins for vulvar intraepithelial neoplasia. N Engl J Med 2009;361:1838-47.

34 Welters MJP, Kenter GG, de Vos van Steenwijk PJ, et al. Success or failure of vaccination for HPV16-positive vulvar lesions correlates with kinetics and phenotype of induced T-cell responses. Proc Natl Acad Sci U S A 2010;107:11895-9.

35 van der Sluis TC, van Duikeren S, Huppelschoten S, et al. VaccineInduced tumor necrosis factor-producing T cells synergize with cisplatin to promote tumor cell death. Clin Cancer Res 2015;21:781-94.

36 Tacken PJ, de Vries IJM, Torensma R, et al. Dendritic-Cell immunotherapy: from ex vivo loading to in vivo targeting. Nat Rev Immunol 2007;7:790-802.

37 Rabik CA, Dolan ME. Molecular mechanisms of resistance and toxicity associated with platinating agents. Cancer Treat Rev 2007;33:9-23.

38 Gadducci A, Tana R, Cosio S, et al. Treatment options in recurrent cervical cancer (review). Oncol Lett 2010;1:3-11.

39 Galluzzi L, Senovilla L, Zitvogel L, et al. The secret ally: immunostimulation by anticancer drugs. Nat Rev Drug Discov 2012;11:215-33.

40 Zitvogel L, Apetoh L, Ghiringhelli F, et al. Immunological aspects of cancer chemotherapy. Nat Rev Immunol 2008;8:59-73.

41 Kang TH, Mao C-P, Lee SY, et al. Chemotherapy acts as an adjuvant to convert the tumor microenvironment into a highly permissive state for vaccination-induced antitumor immunity. Cancer Res 2013;73:2493-504.

42 Bae SH, Park Y-J, Park J-B, et al. Therapeutic synergy of human papillomavirus E7 subunit vaccines plus cisplatin in an animal tumor model: causal involvement of increased sensitivity of cisplatintreated tumors to CTL-mediated killing in therapeutic synergy. Clin Cancer Res 2007:13:341-9.

43 Peng S, Wang JW, Karanam B, et al. Sequential cisplatin therapy and vaccination with HPV16 E6E7L2 fusion protein in saponin adjuvant GPI-0100 for the treatment of a model HPV16+ cancer. PLoS One 2015;10:e116389.

44 Martins I, Kepp O, Schlemmer F, et al. Restoration of the immunogenicity of cisplatin-induced cancer cell death by endoplasmic reticulum stress. Oncogene 2011;30:1147-58.

45 de Villiers EM. Heterogeneity of the human papillomavirus group. $J$ Virol 1989;63:4898-903.

46 Lai C-H, Chang C-J, Huang $\mathrm{H}-\mathrm{J}$, et al. Role of human papillomavirus genotype in prognosis of early-stage cervical cancer undergoing primary surgery. J Clin Oncol 2007;25:3628-34.

47 Schwartz SM, Daling JR, Shera KA, et al. Human papillomavirus and prognosis of invasive cervical cancer: a population-based study. $J$ Clin Oncol 2001;19:1906-15. 